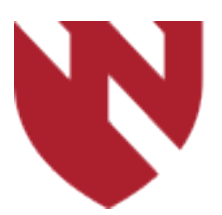

October 2021

\title{
Thoracoscopic Left Atrial Appendage Ligation Complicated by Persistent Left Superior Vena Cava
}

\author{
Rebecca A. Aron \\ University of Nebraska Medical Center \\ Maria deCastro \\ Cedars Sinai Medical Center \\ Kristina L. Koch \\ UNMC \\ Kenneth Neff \\ Loma Linda School of Medicine \\ Tyler Gouvea \\ Vituity Medical Group, Mercy General Hospital
}

Tell us how you used this information in this short survey.

Follow this and additional works at: https://digitalcommons.unmc.edu/gmerj

Part of the Anesthesiology Commons, and the Medical Anatomy Commons

\section{Recommended Citation}

Aron, R. A., deCastro, M., Koch, K. L., Neff, K., , Gouvea, T. Thoracoscopic Left Atrial Appendage Ligation Complicated by Persistent Left Superior Vena Cava. Graduate Medical Education Research Journal. 2021 Oct 04; 3(1).

https://digitalcommons.unmc.edu/gmerj/vol3/iss1/7

This Case Report is brought to you for free and open access by DigitalCommons@UNMC. It has been accepted for inclusion in Graduate Medical Education Research Journal by an authorized editor of DigitalCommons@UNMC. For more information, please contact digitalcommons@unmc.edu. 


\title{
Thoracoscopic Left Atrial Appendage Ligation Complicated by Persistent Left Superior Vena Cava
}

\begin{abstract}
We herein report a 64 year-old male who had an incidental finding of a persistent left superior vena cava (SVC) revealed by intraoperative transesophageal echocardiography (TEE) during a Maze procedure with left atrial appendage ligation. During the intraoperative TEE, an incidental dilated coronary sinus $>1.1 \mathrm{~cm}$ was noted which prompted further evaluation and aided in our ultimate diagnosis. Consequently, significant additional surgical dissection and manipulation were required to isolate the left upper pulmonary vein. This case report reviews the anatomy and embryology of a persistent left SVC, discusses its clinical implications, and identifies surgical considerations for treatment.
\end{abstract}

\section{Keywords}

Dilated coronary sinus, Persistent Left Superior Vena Cava, Thoracoscopic Maze Procedure and Left Atrial Appendage Exclusion

\section{Creative Commons License}

(c) (i) $\Theta \Theta$

This work is licensed under a Creative Commons Attribution-Noncommercial-No Derivative Works 4.0 License. 


\section{Thoracoscopic Left Atrial Appendage Ligation Complicated by Persistent Left Superior Vena Cava}

Rebecca A. Aron', Maria deCastro², Kristina L. Koch ${ }^{1}$, Kenneth Neff ${ }^{3}$, Tyler Gouvea ${ }^{4}$

1 University of Nebraska Medical Center, College of Medicine, Department of Anesthesiology

${ }^{2}$ Cedars Sinai Medical Center, Department of Anesthesiology

${ }^{3}$ Loma Linda School of Medicine, Department of Anesthesiology

${ }^{4}$ Vituity Medical Group, Mercy General Hospital Department of Anesthesiology

https://doi.org/10.32873/unmc.dc.gmerj.3.1.010

\begin{abstract}
We herein report a 64-year-old male who had an incidental finding of a persistent left superior vena cava (SVC) revealed by intraoperative transesophageal echocardiography (TEE) during a Maze procedure with left atrial appendage ligation. During the intraoperative TEE, an incidental dilated coronary sinus $>1.1 \mathrm{~cm}$ was noted which prompted further evaluation and aided in our ultimate diagnosis. Consequently, significant additional surgical dissection and manipulation were required to isolate the left upper pulmonary vein. This case report reviews the anatomy and embryology of a persistent left SVC, discusses its clinical implications, and identifies surgical
\end{abstract} considerations for treatment.

\section{Introduction}

Persistent left superior vena cava (PLSVC) is the most common venous cardiac anomaly, occurring in $0.3-0.5 \%$ of the population. A PLSVC results from failure of regression of the left superior cardinal vein caudal to the innominate vein. This left sided venous structure in most cases drains into the coronary sinus (CS). PSLVC, a right SVC (RSVC), and a bridging innominate vein occur in $65 \%$ of cases. Less commonly, the RSVC will regress, and all venous drainage from the head and upper extremities will be via the PLSVC. ${ }^{2}$

Clinical presentation of PLSVC is variable, however, the majority of these individuals remain asymptomatic. From an electrophysiology standpoint, a dilated coronary sinus may cause cardiac arrhythmias due to stretching of the atrioventricular node and bundle of His. ${ }^{3}$ In addition, a PLSVC in conjunction with an unroofed coronary sinus may manifest with cyanosis, right heart failure, pulmonary hypertension or with stroke like symptoms secondary to a paradoxical embolism. ${ }^{4}$

In our case, the PLSVC was found incidentally on TEE intraoperatively during a Maze procedure and left atrial appendage (LAA) ligation. Consequently, significant additional surgical dissection and manipulation were required in order to isolate the left upper pulmonary vein.

\section{Case}

A 64-year-old male with a history of atrial fibrillation, cerebrovascular accident with brain MRI findings but no residual deficits, hyperlipidemia and hypothyroidism presented for thoracoscopic Maze and left video assisted thoracoscopic surgery and ligation of the LAA. A preoperative CT scan and transthoracic echo were performed and did not reveal a dilated coronary sinus.

Intraoperative transesophageal echo revealed low-normal left ventricular function with no regional wall motion abnormalities, normal right ventricular function, mild mitral regurgitation, moderate aortic valve regurgitation and trivial tricuspid regurgitation. A dilated CS measuring $2.5 \mathrm{~cm}$ was incidentally noted, seen in Fig. 1.

A peripheral IV was placed on the patient's left upper extremity and agitated saline was injected. Bubbles were first seen in the CS with subsequent opacification of the right atrium, diagnosing a PLSVC as shown in Fig. 2. Consent was obtained to use this case for educational purposes.

\section{Discussion}

An incidentally noted dilated CS $>1.1 \mathrm{~cm}$ should prompt evaluation. ${ }^{5}$ Most commonly, a dilated CS results from elevated rightsided pressures associated with pulmonary hypertension or tricuspid regurgitation. It is important, however, to assess for possible PLSVC or anomalous pulmonary venous drainage.

In utero the right anterior cardinal vein forms the right jugular vein and joins with the common cardinal vein to form the superior vena cava. The left anterior cardinal vein forms the left jugular vein, and the drainage from the left upper extremity joins the right anterior cardinal vein forming the left

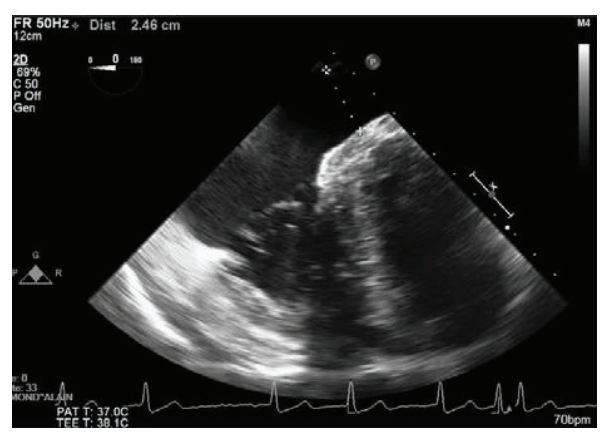

Figure 1. Dilated Coronary sinus measuring $2.5 \mathrm{~cm}$.

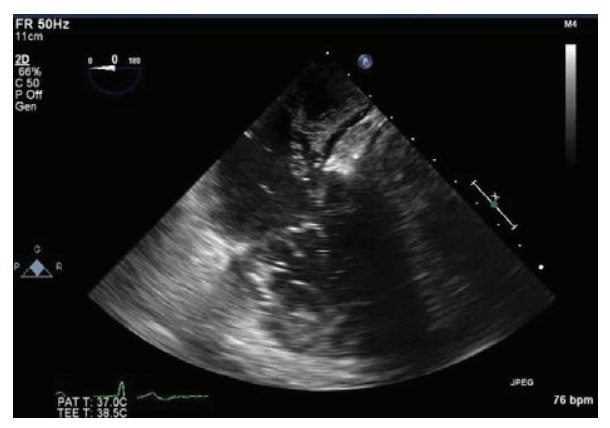

Figure 2. Saline-air microbubble contrast from left upper extremity opacifying the coronary sinus and subsequently right atrium.

brachiocephalic vein. The proximal portion of the left anterior cardiac vein below this anastomosis regresses to become the ligament of Marshall, which lies between the left upper pulmonary vein and the LAA. If this regression fails, a PLSVC occurs which drains to the right atrium via the CS. As shown in Fig. 3 and Fig. 4 on TEE, a PLSVC courses between the LAA and LUPV. Therefore, any view which shows the LAA and LUPV can be useful for diagnosis (e.g., midesophageal four chamber, 45-degree view with the LAA and LUPV clearly in view).

Clinical implications of PLSVC include difficulty with placement of a Swan-Ganz catheter via the left subclavian approach and difficulty with placement of pacemaker leads. ${ }^{2}$ Serious complications from attempts to pass guide wires in adults with PLSVC have been reported, including angina, cardiogenic shock, and cardiac arrest. Additionally, delivery of 
retrograde cardioplegia during cardiac surgery may be ineffective secondary to inadequate myocardial protection. ${ }^{6}$

Because of the proximity of the PLSVC to the LAA, there were relevant surgical implications for this case and the surgical team was immediately notified. PLSVC was confirmed by direct inspection. Isolation of the left upper pulmonary vein and LAA for both the Maze and the LAA ligation were more challenging because of this anatomic variant. Correct identification of the PLSVC potentially avoided inadvertent vascular injury and blood loss. Ultimately, a $45 \mathrm{~mm}$ AtriCure clip was placed, and TEE was used to confirm exclusion of the appendage.

\section{Conclusion}

As PLSVC is commonly asymptomatic, the diagnosis is often made intraoperatively. Pacemaker implantation, pulmonary artery catheter insertion, and retrograde cardioplegia administration are more difficult in the presence of PLSVC. ${ }^{7}$ In our case, because of the anatomic proximity of the PLSVC to the left atrium and LAA, the PLSVC created an intraoperative challenge for the Maze and LAA exclusion. Identification of this anatomic variant and discussion with the surgical team are essential for safe care.

\section{References}

1 Shenoy M, Ali O, Tuliani T, et al. Persistent Left Superior Vena Cava with Absent Right Superior Vena Cava: Out of Mind is Out of Sight? Journal of Clinical Case Reports 2012; 2:102.

2 Goyal S, Sujeeth R, Gita V, et al. Persistent left superior vena cava: a case report and review of the literature. Cardiovascular Ultrasound 2008; 6:50

3 Saha S, Paoletti D, Robertson M. Persistent left superior vena cava - considerations in fetal, pediatric and adult populations. Australas J Ultrasound Med. 2012;15(2):61-66. doi:10.1002/j.2205-0140.2012. tb00228.x

4 Murthy A, Jain A, El-Hajjar M. Unroofed Coronary Sinus Presenting as Cerebral Abscess: A Case Report. Cardiol Res. 2013;4(3):116-120. doi:10.4021/cr273w

5 Mathew J, Ayoub C, Nicoara A, Swaminathan M. Clinical Manual and Review of Transesophageal Echocardiography, 3rd ed. New York: McGraw-Hill; 2019.490.

6 Saha S, Paoletti D, Robertson M. Persistent left superior vena cava - considerations in fetal, pediatric and adult populations. Australas J Ultrasound Med. 2012;15(2):61-66. doi:10.1002/j.2205-0140.2012 tb00228.x

7 Deshpande R, Band M, Kurup V. Persistent Left Superior Vena Cava: Unusual Catheter Position on Chest X-ray Film. Anesthesiology 2017;127(1):165.
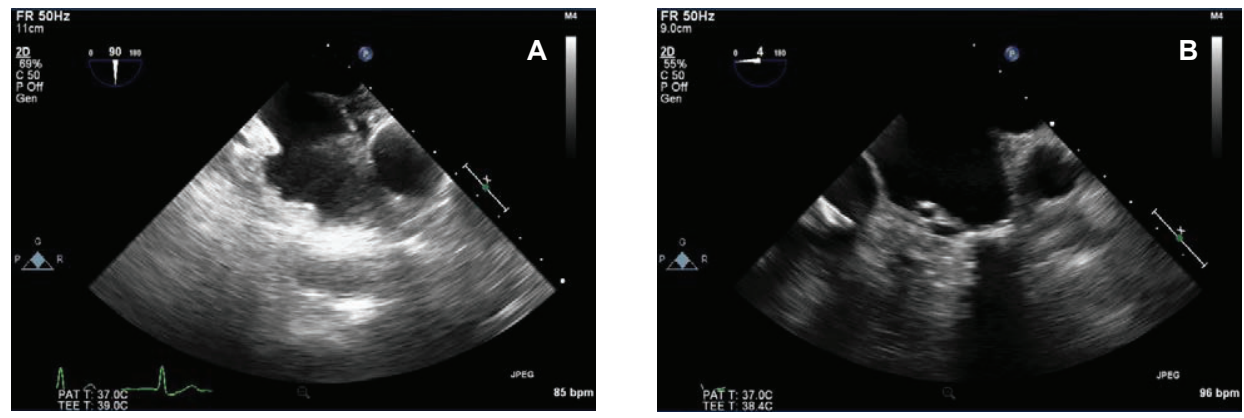

Figure 3 A, B. Relationship of PLSVC between the LAA and LUPV.

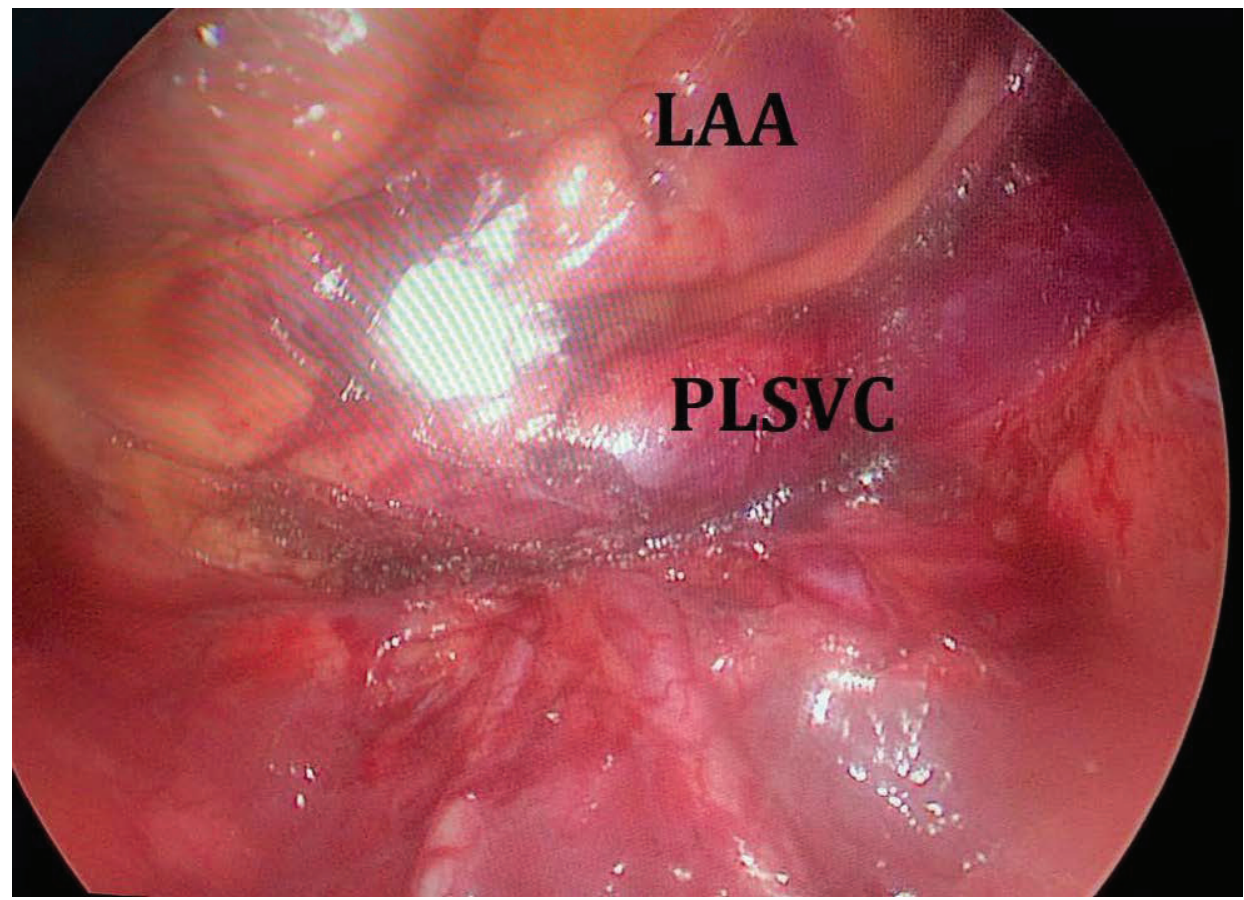

Figure 4. Thoracoscopic view of LAA on superior aspect of field with PLSVC coursing through the middle of the field partially obstructing access to LAA. 